\title{
Sobre o tempo da loucura em Nise da Silveira*
}

\author{
Time in mental illness according to Nise da Silveira
}

Jacileide Guimarães ${ }^{1}$ Toyoko Saeki ${ }^{1}$

\footnotetext{
* Este estudo é parte integrante da tese intitulada: "Sobre o tempo: elogio à instituição negada", de autoria de Jacileide Guimarães com orientação da Professora Doutora Toyoko Saeki.

${ }^{1}$ Escola de Enfermagem de Ribeirão Preto da

Universidade de São Paulo, EERP/USP.

Avenida do Café 1695, A301. 14050-230. Ribeirão Preto-SP.

jaciguim@yahoo.com.br
}

Abstract This research is about time at psychiatric hospitals. After a brief review of the literature on timeand time at a psychiatric hospital, theauthor focused on psychiatry'sapproach and on studies by $\mathrm{N}$ ise da Silveira, a researcher who worked at the Centro Psiquiátrico Nacional do Engenho de Dentro, Rio de Janeiro (now named Centro Psiquiátrico Pedro II), where in 1946 she founded an Occupational Therapy and Rehabilitation Division, which a patient named "theemotionscoping room". Time of mental illness according to N ise is equal to the synthesis of time versus affection, with no considerations towards the sensitivities of scientific knowledge, but instead is a search for the real complexities of the human condition. Referring back on life and then suffering, $\mathrm{N}$ ise instead she considered affection as a sine qua non condition for the understanding of "difference" and "at thelimit" referring to what thepsychiatric jargon called " time and space disorientation ". Considering the trends of theadoption of new policiesin psychiatric carein Brazil, an alternativefor secluded time of mental illnessisa contribution from $\mathrm{N}$ ise da Silveira as a dignifying survival measure in a time of psychosocial care. Key words Time, Psychiatry, Nise da Silveira
Resumo Trata-se de um ensaio sobre a vivência do tempo no âmbito do hospital psiquiátrico. A pós breve incursão acerca da escrita sobre o tempo e o tempo no hospital psiquiátrico, nos detemosno enfoque da psiquiatra epesquisadora N ise da Silveira, cujo trabalho foi desenvolvido no Centro Psiquiátrico Nacional do Engenho de Dentro - Rio de Janeiro (antigo Centro Psiquiátrico Pedro II e atualmentedenominado Instituto M unicipal Nise da Silveira), onde criou, em 1946, a Seção de Terapêutica O cupacional e Reabilitação (STOR), chamada por um interno de "a sala da emoção de lidar". O tempo da loucura em Nise equaciona a síntese tempo versus afeto, sem reservas para com assusceptibilidades deum saber científico, masem busca da real complexidade da condição humana. Reportando-se da vida ao sofrimento, $\mathrm{N}$ ise trouxe 0 afeto como condição sine que non para a compreensão da diferença e no limite para o questionamento do que o jargão psiquiátrico preconizava/esquadrinhava como "desorientado no tempo e no espaço". Com a tendência da reestruturação dos serviços psiquiátricos no Brasil, o tempo revisitado da loucura enclausurada traz a contribuição de Nise da Silveira como atitude digna de sobrevivência em tempos de atenção psicossocial. Palavras-chave Tempo, Psiquiatria, N ise da Silveira 
Escrita sobre o tempo... o tempo e o hospital psiquiátrico

Falar sobre o tempo no âmbito da loucura e seu espaço secular articula, pelo menos, três componentes da história da psiquiatria/saúde mental: 0 paciente psiquiátrico, o trabalhador em saúde mental e o manicômio. Podendo ser sintetizado da seguinte forma: quais os subterfúgios usados pelo paciente psiquiátrico, com história de longa internação, para apreender/registrar o tempo? A negação da cronologia do tempo para os pacientes psiquiátricos instutucionalizado é um fato comprovado pela ausência de símbolos como relógios e calendários nas grandes enfermarias e pavilhões hospitalares e que estão postos na literatura da área. Assim como a guarda dos eventuais relógios de pulso e espelhos e a ambientação geralmenteescura eúmida dos espaços, principalmente, destinados aos indigentes nos hospitais psiquiátricos seculares. Se o tempo instituído, esse então que conhecemos hoje, convencionado pelos relógios e calendários, foi negado ao paciente psiquiátrico institucionalizado e indigente, sendo sua percepção subjetiva de tempo, em geral, considerada como sintoma da doença, de al guma maneira este paciente deve ter reconstruído/reinventado mecanismos de validação. Assim, "qual a trama dos hábitos que sustentam/sustentaram a temporalidade da vida cotidiana" ${ }^{1}$ desses pacientes? Isso porque acreditamos que no ato do conformismo transborda resistência, e o fenômeno tempo atravessa a condição humana de maneira que pode até se travestir no seio de uma mesma sociedade, de forma diversa da convencional - 0 seu aspecto cronológico das sociedades industriais - porém, se manifesta, se expressa na cotidianidade implacável do passar das horas.

E se o tempo é essa "coisa" que não se pode perceber apenas pelos sentidos, mas que também não é só essa "coisa" revelada pelos relógios, não convence o cânone psiquiátrico que assinala o paciente como "desorientado no tempo e no espaço".

Norbert Elias ${ }^{2}$ escreveu um ensaio intitulado Sobre o Tempo, onde discorreu sobre a apreensão do sentido do tempo desde as sociedades ditas primitivas atéas sociedades estatais/industriaise compartilhou conosco uma constatação instigante, a de que ainda hoje meditamos sobre o tempo sem saber se ele é um objeto de processos naturais ou se é um objeto cultural. E conclui: 0 que é, afinal, que realmente indicam os relógios, ao dizermos que dão a hora?

Elias ${ }^{2}$ refereà mistura do conhecido-e-desco- nhecido (instrumental-e mistério) que se opera na síntese dos homens sobre o tempo, destacando queéfácil de compreender que os relógios sejam instrumentos construídos e utilizados em função das exigências da vida comunitária, mas que o tempo tenha igualmente um caráter instrumental é algo que não se entende com facilidade. "Será que seu curso não se desenrola de maneira inexorável, sem levar em conta as intenções humanas? 0 uso lingüístico também contribui para confundir o panorama, dando a impressão de que o tempo é aquele algo misterioso cuja medida é dada por instrumentos de fabricação humana, os relógios".

Já o historiador M arc Bloch ${ }^{3}$ sintetizara que o tempo humano há de ser sempre rebelde tanto à implacável uniformidade como ao seccionamento rígido do tempo do relógio.

A teoria do conhecimento na tradição filosófica se alimentou dessa antinomia sobre a natureza do tempo, gerando a polêmica que opunha de um lado a interpretação do tempo como um dado "objetivo", independente da realidade humana, e de outro, a interpretação "subjetiva", enraizada na natureza humana, sobre o que Elias ${ }^{2}$ considera como hipóteses "artificiais", cujos "debates intermináveis que opõem seus respectivos partidários são estéreis", uma vez que nosso saber resulta de um longo processo de aprendizagem, que não teve um começo na história da humanidade. Todo indivíduo, por maior queseja sua contribuição criadora, constrói a partir de um patrimônio de saber já adquirido, o qual ele contribui para aumentar. E isso não é diferente no que concerne ao conhecimento do tempo.

Este autor ${ }^{2}$ nos alerta que o que um relógio comunica, por intermédio dos símbolos inscritos em seu mostrador, constitui aquilo a que chamamos tempo. Ao olhar o relógio, sei quesão tantas ou quantas horas, não apenas para mim, mas para o conjunto da sociedadea que pertenço. Mas a compartimental ização do tempo em "tempo físico" por um lado e "tempo social" por outro é uma abordagem dicotômica e, por isso, obsoleta, "como se eles existissem e pudessem ser estudados independentemente um do outro". Isso, porém, é impossível. "[...] 0 estudo do 'tempo' é 0 de uma realidade humana inserida na natureza, enão de uma'natureza' e uma realidade humana separadas".

Para Whitrow ${ }^{4}$ a nossa idéia de tempo decorre da reflexão acerca da experiência do presente, mas, no entanto, enquanto a nossa atenção concentra-senessepresente, tendemos a não ter consciência do tempo, porque perdemos a noção de 
duração. E isso podeser afetado demaneira drástica por um conjunto de fatores que nos rodeiam, tais como nosso estado físico geral, pela distorção proporcionada por drogas ou pelo confinamento por longos períodos em ambientes frios ou escuros, sem recurso a relógios. Sendo que, entreosfatores queinfluenciam nosso sentido de duração, porém, o mais amplamente experimentado é nossa idade, pois há um reconhecimento geral de que, à medida que ficamos mais velhos, o tempo, tal como o registram o relógio e o calendário, parece passar cada vez mais depressa.

Conforme 0 autor supracitado, atente-se para 0 alto grau de comprometimento do sentido de duração no manicômio, onde o estado físico geral da pessoa encontra-se afetado, o uso de drogas psicotrópicas interfere na senso-percepção e o confinamento em locais frios e escuros sem 0 recurso de relógios/calendários é lugar comum. E quanto à idade? Não são poucos os pacientes classificados com idade ignorada, e não foram menos os que passaram a ignorá-la no âmbito do manicômio.

A complexificação crescente da sociedade institucionalizou o tempo como dispositivo de alto grau de síntese, imprescindível no mundo ocidental industrializado, "levando todos a se perguntarem cada vez mais, incessantemente, 'Que horas são?', ou 'Que dia é hoje?'”2. M as o que ocorreu com os pacientes psiquiátricos institucionalizados, que embora em uma sociedade que dispõe/enfatiza mecanismos de controle e demonstração/orientação do tempo não os utilizaram? Ou seja, o que subsistiu à orientação temporal convencional destas pessoas por mais de vinte anos em instituições que omitiram o uso de relógios e calendários? Se o tempo "necessita ser sustentado com seqüências que possam criar a sensação de continuidade" ${ }^{1}$ - 0 sentido de duração - quais as "estruturas de sustentação" empregadas por esses pacientes? Desveladas as pretensões de neutralidade da ciência, sabemos que apesar de classificado como desorientado no tempo e no espaço, o paciente psiquiátrico resguarda formas de orientação pessoal, não raro ancoradas em um tempo subjetivo ou, como disse $\mathrm{N}$ ise da Silveira ${ }^{5}$, um tempo sustentado por camadas da experiência do afeto pessoal. M esmo porque, "no hospício, como nas prisões, o tempo objetivo está como se tivesse realmente sido estancado: tem-sea sensação de um presente enorme e vazio" 6 .

Se hoje os serviços substitutivos dos hospitais psiquiátricos ostentam signos de orientação temporal cronológica, no passado não foi assim.
Nos grandes pavilhões dos manicômios, cujos herdei ros estão hoje em vias de desinstitucionalização, naqueles hospícios, os pacientes não tinham o privilégio, do ponto de vista convencional, de disporem de relógios e calendários.

Conforme M offatt ${ }^{6}$, nos hospitais psiquiátricos o dia da alta é indefinido, não se estabelecem prazos terapêuticos. "Em princípio épossível permanecer internado 3, 6 meses, ou 10 anos, dependendo da sorte e do azar. Tudo isso conspira contra a elaboração de um projeto de vida ou, pelo menos, contra a definição de uma data de saída que permita organizar uma forma de perceber, de contar o tempo e, com isso, livrarse um pouco desta sensação de tempo-morto, de tempo-infinito".

Minzoni ${ }^{7}$, em estudo realizado na década de 1970 em um hospital psiquiátrico de uma cidade do interior do Estado deSão Paulo, constatou que na área destinada aos pacientes não se vê relógio, calendário ou espelho. Durante o dia, não existe horário para repouso e os pacientes indigentes não têm acesso ao leito; somente os particulares ealguns considerados melhores o têm. 0 horário das refeições é rígido, sendo trancadas as portas que oferecem acesso a outras áreas do hospital, além do pátio e banheiros. 0 paciente indigente não tem comunicação com o ambiente externo ao hospital, nem pode se comunicar com os familiares por carta ou telefone. A família não participa do tratamento, os dias de visita são regulamentados e nesses dias os familiares não podem circular pela área do hospital. Ficam restritos ao local destinado às visitas. Para os particulares, há liberdade de visitas e comunicação com a família. 0 hospital é rígido em seus regulamentos e rotinas, não permitindo a participação do pessoal de enfermagem e do paciente nas decisões.

Note-se a reprodução, no manicômio, da divisão dos pacientes em classes sociais, em que, para os indigentes, as condições e regulamentos do hospital acirram-se, sem deixar margem para qualquer liberdade. E quanto aos horários rígidos das refeições, Minzoni ${ }^{7}$ também constatou a discrepância em relação com os horários usuais na sociedade extramuro.

Goffman ${ }^{8}$, em sua abordagem sobre as instituições totais, dentre as quais classifica o "hospital para doentes mentais", refere-se ao "tempo morto" nessas instituições, em que o controlerigoroso das necessidades humanaséum fato constatado. Todas as atividades diárias são rigorosamenteestabelecidas em horários, pois uma atividade leva, em tempo determinado, à seguinte, e toda a seqüência deatividades éimposta de cima, 
por um sistema de regras formais explícitas eum grupo de funcionários.

Daí podermos inferir quetais horários, assim como as atividades, rigorosamente estabelecidas eimpostas de cima, não implicam necessariamente, mas muito pelo contrário, no conhecimento dos horários para os internados como apreensão do tempo convencionado na sociedade. Ou seja, por certo, o tempo nas instituições totais enquadra-se no que G offman ${ }^{8}$ denominou de "incompatibilidades das instituições totais" para com as estruturas básicas da sociedade, sobre o que este autor cita a forma de pagamento pelo trabalho realizado e a relação com a família, e aqui acrescentamos, a relação com o tempo.

Tais incompatibilidades geram o queG offman ${ }^{8}$ chamou de "desculturamento" ou "destreinamento", que consistena inabilidade temporária do paciente em enfrentar alguns aspectos de sua vida diária, dentre os quais destacamos o recurso à cronologia do tempo - ou o tempo objetivo - tal como no espaço cultural e social extramuro.

Esse autor ${ }^{8}$ traz exemplos de quea internação causa uma ruptura inicial profunda com os papéis vivenciadosanteriormente pelo pacienteinstitucionalizado, assim como a retirada de seus pertences individuais, remetendo-o a uma "perda do passado". Sobre este aspecto M offatt ${ }^{6}$ refere-sea um passado "congelado" que compete para a ausência ou dificuldade de projeção/perspectiva do futuro.

Nas enfermarias dos hospitais psiquiátricos, em geral, têm-se como mobília "apenas cadei ras e bancos pesados de madeira". Segundo nossa experiência como trabalhadoras e pesquisadoras em saúde mental, podemos acrescentar, bancos e mesas fixos, chumbados ao chão, não podendo ser movidos de um lugar para outro, como, por exemplo, deum local escuro esem ventilação para uma janela, mesmo que com grades, como são as janelas dos manicômios.

Porém, Goffman ${ }^{8}$ nos indica uma avaliação perspicaz no que se refere ao tempo do paciente psiquiátrico institucionalizado ao sugerir que o sentimento de tempo perdido nas instituições totais não sedeveapenasàs condições duras de vida, mas também às perdas de contatos sociais usuais e a impossi bilidade de aí adquirir coisas que possam ser transferidas para a vida extramuro, por exemplo, dinheiro, formação de ligações conjugais, certidão de estudos realizados.

Os jornais e revistas produzidos pelos internados dos hospitais psiquiátricos não lhes dão 0 sentido temporal similarmente atribuído aos relógios ecalendários por serem exibiçõesinstituci- onais (representadas pel os jornais, revistas, esportes internos, festa anual - $0 \mathrm{~N}$ atal e pelo teatro institucional). Tem-se nestas atividades indícios da presença da orientação oferecida pelo relógio e pelo calendário; no entanto, o caráter regulado dessas manifestações parece negligenciar tal orientação convencional, desconectando-se do sentido de duração do tempo. Seja pelo fato de serem atividades semi-erigidas apenas pelos "eleitos", seja pelo fato de serem atividades supervisionadas pela equipe dirigente, seja pelo fato da instantaneidade/momentaneidade - exibição - da ação. Ainda sobreos el eitos, vale destacar que, no hospital psiquiátrico, ser eleito significa ser obediente/subserviente - convertido ou colonizado 8 - , o que por sua vez, implica na ausência dequestionamento sobre qualquer coisa.

0 paciente de hospitais para doentes mentais "parece atingir um novo platô quando aprendeque pode sobreviver ao agir de uma forma que a sociedade considera como capaz de destruí-10" ${ }^{8}$. Supomos que isso se dá porque 0 paciente descobre/inventa formas de construção/sobrevivência. E sobre esse aspecto de sobrevivência do paciente psiquiátrico, nos detemos nas formas de sustentação com relação à sua percepção de tempo. 0 tempo oficialmente negado, mas que se afirma em formas de sobrevivência, como se afirmam outros aspectos da condição do pacientepsiquiátrico institucionalizado por mais de vinte anos. Como constatação de formas de sobrevivência dentro das instituições totais, destaca-se, por exemplo, os "sistemas ocultos de comunicação" em que é empregado "um conjunto especial de convenções de comunicação entre si". Já uma forma de evidenciar a busca de conexão dos pacientes com o tempo objetivo e a constatação de que desejavam transformar aquele "tempo morto" em tempo vivo/vivido, tem-se o que para eles se revestia na idéia de tratamento médico: "a idéia de que a pessoa está passando por tratamento durante vários anos, mas que será útil para o resto da vida, pode dar a al guns pacientes a possibilidade de encontrar um sentido aceitável para o tempo que passam exilados no hospital"8.

O utro aspecto para encontrar um sentido aceitável para o tempo que passam exilados no hospital, usado por alguns pacientes, e maciçamente propugnado pela equipe médica do manicômio, é o recurso à laborterapia - a cura pelo trabal ho, ressalte-se que essa "terapia" foi advogada exclusivamente para os pacientesindigentes. "Uma das virtudes da doutrina de que os hospitais para doentes mentais são hospitais para tratamento de 
pessoas doentes é que os internados, depois de terem dedicado anos de suas vidas a esse tipo de exílio, podem tentar convencer-se de que trabaIharam ativamente para sua cura e que, uma vez curados, o tempo aí dispendido terá sido um investimento razoável e proveitoso. Este sentimento de tempo morto provavelmente explica 0 alto valor dado às chamadas atividades de trabalho e/ ou distração, isto é, atividades suficientemente excitantes para fazer o participante esquecer momentaneamentea sua situação real. Se se pode dizer que as atividades usuais nas instituições totais torturam o tempo, tais atividades 0 matam misericordiosamente" ${ }^{8}$. Atente-se para o fato de que o emprego de trabalho nos hospitais psiquiátricos é um tema amplo e polêmico e que aqui o frisamos apenas no que concerne à apropriação do sentido de tempo, não intencionando adentrar as suas demais particularidades.

Em hospitais psiquiátricos, no seu tempo morto, presente enorme e vazio, tem-se ainda o agravante do esgar da loucura, o estigma/cristalização da patologia na pessoa com sofrimento psíquico, favorecendo a sua classificação e conseqüente reducionismo da pessoa a um depósito de sinais e sintomas do diagnóstico aferido. Entendimento e abordagem que Nise da Silveira subverteu como psiquiatra e estu diosa da condição da pessoa com transtorno psiquiátrico, compreendendo o tempo subjetivo do paciente institucionalizado não apenas como "sintoma da doença", mas como produção de sentido de sua existência.

Se o tempo não passa, mas nós é que passamos por ele $e^{2}$ como passaram os internados indigentes dos hospitais psiquiátricos? De que forma eles passaram, apreenderam em si, o tempo sem símbolos? Quais os subterfúgios utilizados para preencher os emblemas convencionais, ou eles não calculavam, como nós, esse passar fugaz das horas, traduzido na precária constituição dos dias? Responderia Nise: Há sim um tempo do paciente psiquiátrico institucionalizado, um tempo equivocadamenteconsiderado paradoxal porque simultaneamente estancado e acelerado: 0 tempo do afeto subjetivo. Estancado pelo fato de manter-se ancorado no passado ao passo que a vida institucional também não contribui para a sua compreensão e acelerado devido a velocidade da torrente de emoções trazidas pelos afetos particulares.

O olhar de N ise da Silveira vem ao encontro da abordagem da H istória Nova francesa, que prioriza a escrita do cotidiano de sujeitos comuns e anônimos, considerados marginais para a historiografia tradicional centrada na aclama- ção de "majestades" do cenário político das grandes cidades.

Para Le Goff e Nora9 ${ }^{9}$ a escrita da História Nova francesa traz novos problemas que colocam em causa a própria história; novas abordagens que modificam, enriquecem, subvertem os setores tradicionais da história; novos objetos, enfim, aparecem no campo epistemológico da história. Sob influência da economia, da sociologia, da geografia, da antropologia e da psicologia, a história pesquisará o campo econômico-social-mental que permeia e permanece nos acontecimentos.

Essa visão valoriza o levantamento e a consideração de fontes antes negligenciadas. Documentos arqueológicos, pictográficos, iconográficos, fotográficos, cinematográficos, numéricos, orais, enfim, detodo tipo. Todos os meios são tentados para se vencer as lacunas esilêncios dasfontes, mesmo, e não sem risco, os considerados antiobjetivos ${ }^{10}$. Trata-se de uma história que se comunique com as suas fronteiras, seja a economia, a demografia, os costumes, a geografia, a psicologia, a psiquiatria. No dizer de Le Goff ${ }^{11}$ : História dos homens, de todos os homens, não unicamente dos reis e dos grandes. História em movimento, história das evoluções e das transformações, não história estática, história quadro. História explicativa, não história puramente narrativa, descritiva - ou dogmática. Uma nova escrita, tal que expliqueas lacunas, os silêncios da história tradicional, assentando-se tanto sobre esses vazios, quanto sobre os chei os que sobreviveram.

Schmitt ${ }^{12}$, na esteira do legado da História Nova, tece considerações sobre "a história dos marginais", sendo estes os que estão à margem da escrita historiográfica oficial, os que escapam a todas as estruturas de integração numerosas e complementares da sociedade, tais como a escola, a fábrica, a família, dentre outras, e chama a nossa atenção para o seguinte questionamento: “Eles são a-sociais em relação à sociedade dominante. Acaso isso significa que não possuem, em seu 'meio" regras sociais próprias? Ou, inversamente, deve-se pensar que formam uma 'contrasociedade'?". Esse autor destaca que, por escaparem à normalidade das estruturas sociais, os "Ioucos" e os indigentes fazem parte dos marginais, 0 que aglutina sobre a grande maioria dos pacientes psiquiátricos internados em manicômios um duplo caráter de marginalidade: indigente elouco. E nos remete ao pressuposto de que tais pacientes duplamente marginais possuem sim em seu "meio" regras sociais próprias e, que não inversamente, mas por isso mesmo formam uma contra-sociedade, espectro que produziu a sua ma- 
ciça exclusão no século XVII ${ }^{13}$. Daí a incursão por uma escrita da história que permite a investigação dosmarginais como sujeitos detentores deum discurso social que fala não apenas do seu lugar de produção, mas também denuncia a centralidade autoritária do discurso oficialmente vigente. Assim, o paciente psiquiátrico institucionalizado, classificado como louco e indigente denuncia a supremacia de um discurso da normalidade e de uma estratificação do seu poder aquisitivo.

AindaSchmitt ${ }^{12}$ nos alerta para o cuidado que sedeveter com as palavras que escapam do silêncio, pois vêm de lugares da repressão e por isso atestam antes demais nada o funcionamento bem ordenado da instituição judiciária, que aqui não perde o sentido se fizermos a alusão à instituição psiquiátrica. D efato, a hi pótese básica é a de que uma sociedade serevela por inteiro no tratamento de suas margens, daí a contribuição essencial da história da marginalidade: preencher não somente as margens da história, mas também possibilitar uma rel eitura da história do centro, da versão oficial.

Por isso, intencionamos discutir o entendimento de Nise da Silveira sobre o tempo da loucura, posto que um tempo dividido em físico ou social de forma estanque não satisfaz a compreensão do tempo simultaneamente objetivo versus subjetivo, que éo tempo do viver.

A emoção de lidar: o tempo da loucura em Nise da Silveira

N ise M agal hães da Silvei ra nasceu em M aceió em 15 defevereiro de 1905. Formou-sepelaFaculdadedeM edicina da Bahia em 1926. Em 1933, aprovada por concurso público, torna-se psiquiatra da antiga Assistência a Psicopatas e Profilaxia no Rio de Janeiro. Em 1936, foi presa como comunista pela ditadura de Getúlio Vargas por porte de "livros subversivos" (livros de cunho marxista), permanecendo um ano e oito meses afastada do serviço público por motivos políticos. Readmitida no serviço público em 1944, fundou em 1946 a ST OR do Centro Psiquiátrico Nacional no Engenho de Dentro no Rio de Janeiro. Em 1952, a partir do trabal ho desenvolvido nesta seção do hospital, criou o Museu de Imagens do Inconsciente. Mantinha contato eintercâmbio com Carl Jung, de quem traz grande influência para o Brasil através de cursos, simpósios e conferências, além da aplicação prática de contribuições junguianas e da publicação de vários estudos relacionados ${ }^{14}$. Em carta a Arnaldo Alves da M otta, Nise conta que um dos doentes denominou as realizações de seu trabalho emoções de lidar, o que levou a substitui ção interna do "áspero título terapêutica ocupacional por Emoções de Lidar" ${ }^{15}$.

Psiquiatra e pesquisadora diferenciada pelo seu método de abordagem junto aos internados psicóticos, em geral institucionalizados de longa internação, Nise realizou o que hoje se tem claro como verdadeira revolução para os moldes psiquiátricos da época. Contrapondo-se aos métodos coercitivos e invasivos de tratamento da loucura, se posicionou a favor da compreensão do sofrimento psíquico e do máximo zêlo para com a pessoa doente, 0 que Ihe rendeu opositores ferrenhos, defensores de uma psiquiatria "moderna", impositiva e autoritária ${ }^{16}$. Atualmente, énotório não só o êxito da terapêutica empregada por Nise, mas também o valor artístico das obras realizadas pelos doentes sob seus cuidados de 1946 atéo fim desua vidano ano de 1999, quando ainda mantinha vínculo com o hospital e os doentes. "A psiquiatria humanitária, carregada de afeto, que se identifica com o sofrimento esem perder a lucidez, encontra sua síntese nesta mulher detentora dos opostos: fraca/forte, frágil/firme, tranqüila/explosiva, criativa/repetitiva, compreensiva/intransigente. Nise é um anjo duro" ${ }^{17}$.

$\mathrm{N}$ ise colocara a questão do tempo do paciente psiquiátrico, destacando a impossibilidade de comunicação e, portanto, do estabelecimento de uma relação satisfatória entre duas pessoas, se cada uma delas estiver viven do em espaço etempo diferentes. Sobre o que ressaltava ainda a relação indispensável psiquiatra-doente e alertava para o baixo número de profissionais queselembram de considerar a peculiaridade do tempoespaço do internado, dando-se por satisfeitos em investigar a orientação no mundo externo: "Que dia éhoje?", “Que horas são?", “Quelugar é este?”, "Onde você está?" e outras perguntas do mesmo nível. Considerando ainda que dizer queo doente está orientado ou desorientado terá pouca significação para a relação profissional-paciente. "Faltará ainda muito para que seja penetrada a situação vivida por aquele em seu próprio espaço-tempo interior"'.5.

Nisejá equacionara a preocupação do pensamento sociológico ${ }^{2}$ sobre a compartimentalização caduca do tempo em físico por um lado e social por outro, dicotomia que redunda na obsolescência de uma abordagem que pretende dois tempos divididos como se eles existissem e pudessem ser estudados independentementeum do outro. Sobrepujando essa divisão caduca do tempo, denunciava a unilateralidade prevalecente na 
abordagem da ciência psiquiátrica, notadamente de orientação cartesiana-newtoniana, onde a visão objetiva aprisiona eimpede a consideração da existência de outro modus operandi, subjetivo, impregnado pela vivência da pessoa com sofrimento psíquico institucionalizada, portanto, a estrutura desustentação da sua percepção detempo passa necessariamente por afetos intensos estancados ou não. Sendo muitas vezes necessário por parte do terapeuta o estabelecimento de um vínculo inicialmente construído através de um nível não verbal de interação, pautado no acolhimento e na confiança da compreen são $0^{18}$.

Considerando a retroalimentação dos diferentes sistemas de percepção do mundo, o objetivo e o subjetivo, e a conseqüente superação de um tal entendimento estanque entre tempo físico e social, que predomina no modo objetivo na abordagem psiquiátrica, Nise referia-seà dificuldade para se alcançar, se penetrar terapeuticamente, na situação vivida pelo doenteem seu próprio espaço-tempo subjetivo. Assim, guiando-se por uma inter pretação deconjunto, orientada por conhecimentos de outras áreas como mitologia, filosofia, sociologia eantropologia, nos dava uma pista de como se encontrar com o tempo do doente através das suas histórias de vida. Em sua vivência profissional, Nise verificou ter sido a partir de uma intensa situação afetiva que o fluir do tempo "estancou" para as pessoas com grande sofrimento psíquico. As idéias, os afetos que permanecem dominantes durante todo o curso do processo psicótico, derivam sempredas situações queabsorviam o indivíduo antes da doença, como se o tempo parasse ${ }^{5}$. Porém, um tempo centrado no afeto, aparentemente "parado" mas passível de compreensão e desvelamento para a própria evolução da terapêutica, uma vez considerada a sua dinâmica interior, a de um tempo calcado em afetos intensos. 0 afeto anterior, ou seja, a situação na qual eclodiu o processo psicótico, que culminou na internação psiquiátrica, seria, portanto, a chave para a conexão entre os tempos subjetivo do doente e o tempo objetivo do mundo, esteúltimo o tempo no qual estamos todos mergulhados, o veio da normalidade.

Hirata ${ }^{19}$, ao estudar a contribuição da psicologia analítica acerca da conceituação de tempo e de descompasso emocional, destaca o pensamento de que quanto mais emotiva uma vivência, tanto mais viva e duradoura éa sua lembrança. Assim, as emoções são o marca-passo da alma, do relógio anímico.

Tem-se, então, o cerne do disparate do saber orientado exclusivamente para a objetividade da ciência e, portanto, do visível, do mensurável. A psiquiatria tradicional, em seus excessos, tem sua própria camisa de força, traduzida na dissociação dos tempos subjetivo e objetivo com predomínio deste último como "o saber legítimo" do profissional sobre o doente e, em última instância, traduzido na realidade em que se tornaram os hospitais psiquiátricos: depósito de loucos.

A cultura psiquiátrica se distancia do doente através de dizeres/verdades como "desorientado no tempo e no espaço", quando deveria perguntar sobre que tempo e que espaço? Ou ainda quando declara um tal "embotamento afetivo", sem intercambiar as possibilidades simbólicas da existência do doente, que para Nise perfazem a síntese tempo-espaço-afeto. Determinado momento do afeto é a porta de entrada do processo psicótico que gera a institucionalização e todo esse processo passa a ser a referência de tempoespaço para o doente, ou como disse Nise, "verificamos que as vivências do tempo acham-seinstintivamente interligadas aos intensos afetos do doente". Note-sea delicadeza de tal encadeamento, sem pretensão classificatória, sem nenhuma necessi dade de definiç̧ão da loucura ${ }^{20,21}$, um cuidado que não desconsiderava a diferença ou intensidade dos estados mentais, mas também não os agrilhoava na desvantagem. Em 1999, ano em que Nise viria a falecer, Pedro Pellegrino ${ }^{22}$ dizia na apresentação da segunda edição de Cartas a Spinoza, escrito por ela: “Nise sonha alto". E quanto mais lutamos por uma assistência psiquiátrica brasileira pautada na atenção psicossocial, tanto mais comprovamos a atualidade do alto sonho de Nise, que não se atrevia a definir a loucura, fazia muito mais, acolhendo-a e intervindo incansavelmente para o resgate da dignidade do doente que ela preferia chamar pelo seu nome próprio. Como disse Pellegrino22: “Ave Nise!".

\section{Considerações finais}

0 tempo, essa "coisa" que nos atravessa, se transmuta, mas não se dá ao encarceramento, não se contém às amarras disso ou daquilo e nem tão pouco amarra-nos, porquenão somos os mesmos deum instanteatrás, não selimita nas pretensões desta ou daquela ciência.

0 tempo morto dos hospitais psiquiátricos, por exemplo, neste início de século XXI, já não é mais "natural", ou seja, em vias de desinstitucionalização, o objetivo é recuperar não só o "tempo perdido" mas o próprio sentido de tempo. As experiências neste âmbito vêm imprimindo ou- 
tras formas de lidar. E na tendência compreensiva-inclusiva, Nise da Silveira foi precursora e mantém-se com extraordinária atualidade.

Nisesintetizou a necessidade da consideração do tempo versus afeto nos transtornos psiquiátricos, processos responsáveis por grande número de pacientes institucionalizados de longa internação. Sem reservas para com as susceptibilidades de um saber médico, buscava além de um esquadrinhamento "científico" à condição humana da pessoa com sofrimento psíquico. Reportando-se da vida ao sofrimento, Niseventilou a pers-

\section{Colaboradores}

J Guimarães trabal hou na concepção teórica, elaboração e redação final do texto; T Saeki trabaIhou na concepção teórica e na organização do texto.

\section{Referências}

1. M offatt A. Terapia de crise: teoria temporal do psiquismo. 3ạ. ed. São Paulo: Cortez; 1987.

2. Elias N . Sobreo tempo. Rio de Janeiro:JorgeZahar; 1998.

3. Bloch M. Introdução à história. Portugal: Publicações Europa-América Ltda; 1997.

4. Whitrow GJ. 0 tempo na história: concepções do tempo da préhistória aos nossos dias. Rio de Janeiro: Jorge Zahar; 1993.

5. Silveira N. O M undo dasimagens. São Paulo: Ática; 2001.

6. Moffatt A. Psicoterapia do oprimido: ideologia etécnica da psiquiatria popular. 5ạ. ed. São Paulo: Cortez; 1984.

7. M inzoni M A. Assistência deenfermagem ao doentemental internado: análise deuma experiência detreinamento de atendentes em hospital psiquiátrico [tese de livre-docência]. Ribeirão Preto (SP): Escola de Enfermagem de Ribeirão Preto, Universidade de São Paulo; 1975.

8. Goffman E. M anicômios, prisões e conventos. São Paulo: Perspectiva; 1974.

9. LeGoff J, Nora P. H istória: novos problemas. 4a. ed. Rio de Janeiro: Francisco Alves; 1995.

10. ReisJC. Nouvelle histoire e tempo histórico: a contribuição de Febvre, Bloch e Braudel. São Paulo: Ática; 1994.

11. Le Goff J. A história nova. In: Le Goff J, Chartier R, Revel J, organizadores. A história nova. 4ạ. ed. São PauIo: M artins Fontes; 1998. p.25-64.

12. Schmitt J-C. A história dos marginais. In: Le Goff J, Chartier R, Revel J, organizadores. A história nova. 4a. ed. São Paulo: Martins Fontes; 1998. p. 261-290. pectiva de entendimento e compreensão acerca do tempo da loucura. 0 tempo no hospital psiquiátrico, o "tempo morto", porém passível de sustentação para os que vivem institucionalizados e passível de compreensão para os que desejem conhecêlo.

Em uma perspectiva de aten ção psicossocial, a compreensão de $\mathrm{N}$ ise acerca do tempo da loucura traz uma contribuição que compete para o êxito da substituição dos hospitais e das formas arcaicas de abordagem do paciente psiquiátrico, favorecendo a satifação na emoção de lidar.
13. Foucault M. História da loucura na Idade Clássica. 3ạ ed. São Paulo: Perspectiva; 1993.

14. Silveira N. Gatos, a emoção de lidar. Rio de Janeiro: Léo Christiano Editorial; 1998.

15. Silveira N. Carta para Arnaldo Alves da Motta. In Motta AA. Nise da Silveira, 100 anos de emoções de lidar. Junguiana 2005; 23: 7-21.

16. Motta AA. Nise da Silveira, 100 anos de emoções de lidar. Junguiana 2005; 23, 2005, p. 7-21.

17. Valcazaras L. Anjo duro: um salto em queda livre [ peça de teatro]; 1998

18. Aguiar J. Dossiê Jung: Nise, no Brasil a pioneira. EntreLivros 2006; 15:42-43.

19. Hirata RA. 0 complexo de chronos e o descompasso emocional. Junguiana 2005;. 23: 67-77.

20. Nise da Silveira - vida e obra [vídeo]. Disponível em: http://www.ccs.saude.gov.br/nise_da_silveira

21. Memória da loucura [vídeo]. Disponível em: http:// www.ccs.saude.gov.br

22. Pellegrino PG. Um bilhete às cartas. In: Silveira $\mathrm{N}$. Cartas a Spinoza. 2a. ed. Rio de Janeiro: Francisco Alves; 1999.

Artigo apresentado em 22/12/2005

A provado em 20/04/2006

Versão final apresentada em12/09/2006 